\title{
INFLUÊNCIA DA CONDIÇÃO E PERÍODO DE ARMAZENAMENTO NA GERMINAÇÃo DE SEMENTES DE PITAYA VERMELHA ${ }^{1}$
}

\author{
RENATA APARECIDA DE ANDRADE², INEZ VILAR DE MORAIS OLIVEIRA³, \\ ANTONIO BALDO GERALDO MARTINS ${ }^{4}$
}

\begin{abstract}
RESUMO - O experimento foi conduzido no Laboratório de Sementes do Departamento de Produção Vegetal da Faculdade de Ciências Agrárias e Veterinárias - UNESP - Câmpus de Jaboticabal-São Paulo, utilizando sementes extraídas de fruto maduro de pitaya, as quais foram lavadas, secadas em condição ambiente por 24 horas e acondicionadas em sacos de papel, dispostas segundo os tratamentos a serem realizados: 3 condições de armazenamento das sementes: ambiente; câmara seca ( $16-18^{\circ} \mathrm{C}$ e $60 \%$ UR) e câmara fria ( $10^{\circ} \mathrm{C}$ e $60-70 \%$ UR), e 4 tempos de armazenamento: 7 ; 14 ; 21 e 28 dias após a extração das sementes, além da semeadura logo em seguida à extração das sementes (testemunha). Após esses períodos, as sementes foram acondicionadas em caixas gerbox, tendo como substrato papel de filtro e mantidas em câmara de germinação à temperatura constante de $25^{\circ} \mathrm{C}$. Com base nos resultados encontrados, pode-se concluir que as sementes de pitaya vermelha podem ser armazenadas em câmara fria por até 28 dias sem prejuízos à porcentagem de germinação.
\end{abstract}

Termos para indexação: Hylocereus undatus; germinação; armazenamento.

\section{INFLUENCE OF THE CONDITION AND STORAGE PERIOD IN GERMINATION OF RED PITAYA SEEDS}

\begin{abstract}
The experiment was carried out in the Department of Vegetable Production of the Faculdade de Ciências Agrárias e Veterinárias Campus of Jaboticabal-São Paulo State - Brazil, using seeds that were extracted from ripe fruit, that were washed, drying in environmental condition during 24 hours and conditioned in paper bags, disposed according to the treatments: 3 storage conditions of the seeds: environmental; dry chamber $\left(16-18^{\circ} \mathrm{C} \mathrm{e} 60 \% \mathrm{UR}\right)$ and cold chamber $\left(10^{\circ} \mathrm{C} \mathrm{e} 60-70 \% \mathrm{UR}\right)$, and 4 storage periods: $7,14,21$ and 28 days after the extraction of the seeds, besides of the seedling immediately of the extraction of the seeds. After these periods the seeds were conditioned in gerbox boxes, having as substrate filter of paper and maintained in a germination chamber with a constant temperature of $25^{\circ} \mathrm{C}$. Based on the results, it is possible to conclude that the seeds of red pitaya can be storage in cold chamber for until 28 days without damage in percentage of germination.
\end{abstract}

Index terms: Hylocereus undatus; germination; storage.

A pitaya é uma planta originária da América e se encontra distribuída nos países da Costa Rica, Venezuela, Panamá, Uruguai, Brasil, Colômbia e México, sendo os dois últimos os principais produtores mundiais. É uma planta perene, crescendo comumente sobre árvores ou pedras; têm raízes fibrosas, abundantes e desenvolve numerosas raízes adventícias que ajudam na fixação e na obtenção de nutrientes; os talos (caules) são triangulares, suculentos e apresentam espinhos com 2 a 4 $\mathrm{mm}$ de largura. A flor é hermafrodita, de coloração branca, grande (mede cerca de 20 a $30 \mathrm{~cm}$ de largura) e se abre durante a noite. O fruto é globoso ou subgloboso, mede de 10 a $20 \mathrm{~cm}$ de diâmetro, podendo ser de coloração amarela ou vermelha, coberto com brácteas (escamas). As sementes medem aproximadamente $3 \mathrm{~mm}$ de diâmetro e são muito numerosas, de coloração escura e se encontram distribuídas em toda a polpa (Canto, 1993). Os frutos da pitaya vermelha (Hylocereus undatus Haw) são vermelhos externamente, sendo muito atrativos ao consumidor, com polpa esbranquiçada, de sabor agradável, levemente adocicado, apresentando um grande número de diminutas sementes, de coloração preta.

A conservação das sementes, de modo geral, é de grande importância, e o armazenamento, uma vez aplicado de modo adequado, vai diminuir a velocidade de deterioração, que se caracteriza por ser processo irreversível (Delouche et al., 1973; Melo et al., 1998, citados por Cabral et al., 2003). O armazenamento de sementes comercias, ou seja, aquelas cujo período de armazenamento vai da colheita à semeadura no ano agrícola, pode ser por poucos dias ou por períodos maiores ( 6 a 8 meses) e objetiva a conservação da qualidade fisiológica das sementes (Carvalho \& Nakagawa, 2000). Segundo Gómez-Campo (2002), é possível conservar sementes durante longos períodos de tempo através da dessecação e manutenção em baixa temperatura. Esta técnica tão simples favorece a conservação de germoplasma vegetal. De acordo com Ferreira (1988), citado por Cisneiros et al. (2003), a conservação do germoplasma é um fator altamente relevante dentro do contexto de um sistema de recursos genéticos, pois é através da conservação a curto, médio e longo prazos que o material se torna disponível para a comunidade. Em um banco de germoplasma, segundo Goedart (1988), citado por Cisneiros et al. (2003), é essencial conhecerem-se as características das sementes de cada espécie a ser armazenada, assim como os procedimentos adequados para sua conservação e os métodos apropriados para determinar a viabilidade inicial e a monitoração da sua viabilidade durante o armazenamento. Segundo Popinigis (1985), geralmente a longevidade é aumentada conservando-se a semente com baixo teor de umidade e baixa temperatura.

Segundo Carvalho \& Nakagawa (2000), o armazenamento das sementes sofre a influência de diversos fatores, relacionados à qualidade inicial da semente (vigor das plântulas ascendentes; condições climáticas durante a maturação das sementes; grau de maturação no momento da colheita; ataque de pragas e doenças; grau de injúria mecânica) e às características do ambiente (umidade relativa do ar ou teor de água das sementes; temperatura do ar; ação de fungos e insetos de armazenamento; embalagem).

A pitaya encontra-se entre as frutíferas tropicais pouco conhecidas, porém com elevado potencial para os mercados interno e externo. No entanto, deve haver intensificação das pesquisas, visando principalmente à obtenção de informações básicas sobre a cultura e que estas possam ser utilizadas na prática pelos produtores. Nesse contexto, realizou-se o presente trabalho, com o objetivo de avaliar a influência da condição e período de armazenamento das sementes de pitaya em sua porcentagem de germinação.

O experimento foi conduzido no Laboratório de Sementes, localizado no Departamento de Produção Vegetal da Faculdade de Ciências Agrárias e Veterinárias - UNESP - Câmpus de Jaboticabal-São Paulo. As sementes foram extraídas de fruto maduro, lavadas em água corrente, colocadas para secar à sombra durante 24 horas e acondicionadas em sacos de papel, dispostas segundo os tratamentos a

\footnotetext{
${ }^{1}$ (Trabalho 139/2004). Recebido: 10/09/2004. Aceito para publicação: 06/04/2005.

${ }^{2}$ Eng. Agr., Msc, Aluna de Pós-Graduação em Agronomia - Produção Vegetal - UNESP - FCAV - Depto de Produção Vegetal. Via de acesso Prof. Paulo Donato Castellane, s/n. Cep: 14884-900. Jaboticabal-SP. Tel/Fax: (16)32092668. e-mail: reandrad@ @cav.unesp.br. Bolsista CNPq.

${ }^{3}$ Eng. Agr., Msc, Doutoranda em Agronomia - Área de Produção Vegetal, Depto. de Produção Vegetal. e-mail: inezvilar@ yahoo.com. Bolsista CAPES.

${ }^{4}$ Eng. Agr., Prof. Dr., Departamento de Produção Vegetal. FCAV/UNESP. e-mail: baldo@ fcav.unesp.br
} 
serem realizados. Os tratamentos foram constituídos por 3 condições de armazenamento das sementes: ambiente; câmara seca $\left(16-18^{\circ} \mathrm{C}\right.$ e $60 \%$ UR) e câmara fria $\left(10^{\circ} \mathrm{C}\right.$ e $60-70 \%$ UR), e 4 períodos de armazenamento: 7 ; 14; 21 e 28 dias após a extração das sementes, mais a testemunha $(0$ dias). Após esses períodos, as sementes foram acondicionadas em caixas gerbox, sobre o substrato papel de filtro e mantidas em câmara de germinação, à temperatura constante de $25^{\circ} \mathrm{C}$. A escolha pelo uso do papel de filtro e da referida temperatura foi baseada em resultados encontrados em estudos preliminares. O delineamento experimental foi o inteiramente casualizado, em esquema fatorial 3 x 5, sendo 3 condições de armazenamento e 5 períodos de armazenamento (incluindo a testemunha). Para cada tratamento, foram utilizadas 4 repetições com 25 sementes cada. Para fins de análise estatística, os dados de porcentagem de germinação foram transformados em $\operatorname{arc}-\operatorname{sen} \sqrt{x / 100}$.

As médias foram comparadas pelo teste de Tukey, a 5\% de probabilidade. Realizou-se avaliação diária da germinação das sementes, até que fosse atingida a germinação máxima, totalizando 56 dias (8 semanas), de tal maneira que se obtiveram a porcentagem de germinação e o tempo médio para germinação, dados estes agrupados em períodos semanais para fins de análise. Foram consideradas sementes germinadas aquelas que emitiram a radícula.

Pelos resultados obtidos, verifica-se que não houve diferença significativa para os valores de porcentagem de germinação durante o tempo de armazenamento das sementes (Tabelas 1 e 2). No entanto, quando se comparam os valores de porcentagem de germinação das sementes na primeira semana após a instalação do experimento, quando se relaciona à condição de armazenamento a que foram submetidas (Tabelas 1 e 3), o armazenamento em câmara fria proporcionou maiores valores para o parâmetro avaliado, acordando com Vertucci \& Ross (1993), os quais relatam que, em geral, condições de baixa temperatura são as mais recomendadas para armazenar sementes. Não houve interação significativa entre tempo e condição de armazenamento das sementes (Tabela 1). Resultados contraditórios foram observados por Ferreira \& Gentil (2003), os quais verificaram que o armazenamento de sementes de camu-camu (Myrciaria dubia) em condições de baixa temperatura $\left(10^{\circ} \mathrm{C}\right)$ não foi favorável, havendo perda de viabilidade e vigor das sementes.
TABELA 1 - Resumo do quadro de análise de variância do experimento. Teste de Tukey, $5 \%$ de probabilidade.

\begin{tabular}{ccc}
\hline & \multicolumn{2}{c}{ F } \\
& Primeira Semana & Final \\
\hline Fator A & $11.1566^{* *}$ & $3.1366 \mathrm{NS}$ \\
\hline Fator B & $.8672 \mathrm{NS}$ & $2.8074^{*}$ \\
\hline Fator A x B & $2.1469 \mathrm{NS}$ & $.4844 \mathrm{NS}$ \\
\hline Desvio-padrão & 7.8310 & 9.0000 \\
\hline CV & 13.1723 & 11.8566
\end{tabular}

Fator $\mathrm{A}=$ condição de armazenamento; Fator $\mathrm{B}=$ período de armazenamento (dias)

TABELA 2 - Porcentagem de germinação de sementes de pitaya, na primeira semana após instalação, e ao final do experimento (56 dias), quanto ao período de armazenamento.

\begin{tabular}{ccc}
\hline & \multicolumn{2}{c}{ Porcentagem de Germinação } \\
\cline { 2 - 3 } $\begin{array}{c}\text { Período de Armazenamento } \\
\text { (dias) }\end{array}$ & Primeira Semana & Final \\
\hline $\mathbf{0}$ & $59,41 \mathrm{a}$ & $82,16 \mathrm{a}$ \\
$\mathbf{7}$ & $62,48 \mathrm{a}$ & $76,13 \mathrm{a}$ \\
$\mathbf{1 4}$ & $56,53 \mathrm{a}$ & $77,63 \mathrm{a}$ \\
$\mathbf{2 1}$ & $59,42 \mathrm{a}$ & $71,73 \mathrm{a}$ \\
$\mathbf{2 8}$ & $59,42 \mathrm{a}$ & $71,88 \mathrm{a}$ \\
\hline
\end{tabular}

Médias seguidas de mesma letra na coluna não apresentam diferença significativa. Teste de Tukey, $5 \%$ de probabilidade.

O experimento teve um total de oito semanas, e os valores de porcentagem de germinação semanais encontram-se na Figura 1, na qual é possível observar uma semelhança no comportamento desta espécie frutífera quanto à germinação, aos 7 e 14 dias, em relação à testemunha (0 dia de armazenamento) e entre as condições de armazenamento testadas. No entanto, aos 21 e 28 dias, ocorreu queda na porcentagem de germinação máxima para as sementes armazenadas em condição ambiente e em câmara seca. Quanto à condição de armazenamento, podese verificar que, para todos os períodos, foram observados maiores valores de porcentagem de germinação das sementes quando estas foram submetidas ao armazenamento em câmara fria. Para todas as condições testadas, já na segunda semana após a instalação, observa-se um pico
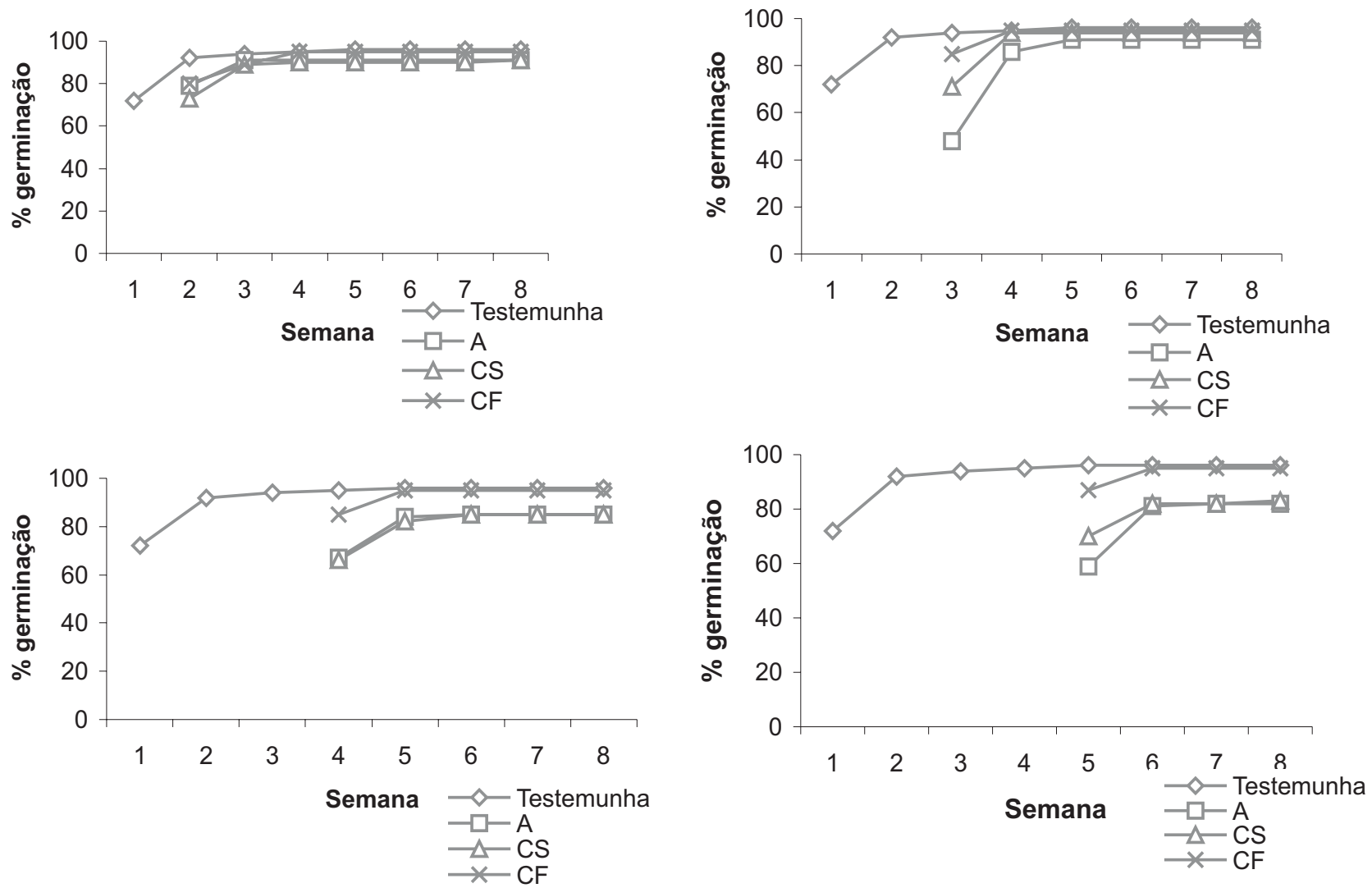

FIGURA 1 - Evolução semanal da porcentagem de germinação de sementes de pitaya, quanto ao tempo $(\mathrm{a}=7$ dias; $\mathrm{b}=14$ dias; $\mathrm{c}=21$ dias, e d = 28 dias, todos comparados com a testemunha) e condição de armazenamento ( $\mathrm{A}=$ ambiente; $\mathrm{CS}=$ câmara seca, e CF = câmara fria). 
na porcentagem de germinação e um ganho muito pequeno neste valor nas semanas seguintes, ocorrendo então a estabilização. Resultados contraditórios foram encontrados em estudo realizado objetivando avaliar a influência do período de armazenamento na precocidade de germinação de sementes de mangaba (Hancornia speciosa), onde Oliveira et al. (2003) observaram que os melhores resultados, tanto para porcentagem de germinação como para o índice de velocidade de germinação (IVG), ocorreram no tempo de armazenamento de 0 dia (82\% e 0,293$)$, sendo ainda observados os valores de $44 \%$ de germinação e $\mathrm{IVG}=0,124$ para o período de 7 dias, não havendo germinação para os demais tempos observados (14; 21 e 28 dias). Os mesmos autores, testando a influência de 2 condições de armazenamento (ambiente e câmara seca) e 4 períodos de armazenamento ( $0 ; 7 ; 14$ e 21 dias) para sementes de umbu (Spondias tuberosa), não encontraram diferença significativa quanto à porcentagem de germinação, semelhante ao observado no presente trabalho. Em estudo realizado com sementes de Tabebuia aurea, Cabral et al. (2003) também não encontraram diferença significativa quanto ao tempo de armazenamento (60; 90 e 120 dias) em relação à porcentagem de germinação das sementes, as quais mantiveram a viabilidade por até 120 dias, com altos percentuais de germinação, variando de 88 a $97 \%$. No entanto, Borges et al. (2003), estudando a influência do período de armazenamento na germinação de sementes da mangueira 'Espada' $(0$; $7 ; 14 ; 21$ e 28 dias), concluíram que não se deve realizar o armazenamento das mesmas.

TABELA 3 - Porcentagem de germinação de sementes de pitaya submetidas a diferentes condições de armazenamento, na primeira semana após instalação, e ao final do experimento (56 dias).

\begin{tabular}{ccc}
\hline & \multicolumn{3}{c}{ Porcentagem de Germinação } \\
\cline { 2 - 3 } Condição de Armazenamento & Primeira Semana & Final \\
\hline Ambiente & $54,64 \quad \mathrm{~b}$ & $73,89 \mathrm{a}$ \\
Câmara Seca & $57,75 \quad$ b & $73,81 \mathrm{a}$ \\
Câmara Fria & $65,96 \mathrm{a}$ & $80,02 \mathrm{a}$ \\
\hline
\end{tabular}

Médias seguidas de mesma letra na coluna não apresentam diferença significativa. Teste de Tukey, $5 \%$ de probabilidade.

As sementes de pitaya vermelha podem, portanto, ser armazenadas em câmara fria, por 28 dias, sem prejuízo à germinação. Estudos futuros poderão ser realizados para a observação da possibilidade de maiores períodos de armazenamento para esta frutífera.

\section{REFERÊNCIAS}

BORGES, C. A. M.; SIQUEIRA, D. L.; DIAS, D. C. F. S. Influência da massa e período de armazenamento das sementes na germinação e crescimento de mudas da mangueira 'Espada'. Pesquisa Agropecuária Brasileira. Ago. 2003. vol. 38. n.8. p.999-1004.

CABRAL, E.L.; BARBOSA, D.C.A.; SIMABUKURO, E.A. Armazenamento e germinação de sementes de Tabebuia aurea (manso) Benth. \& Hook. f. ex. S. Moore. In: Acta Bot. Bras. v.17 n.4 São Paulo out./dez. 2003.

CANTO, A.R. El cultivo de pitahaya en Yucatan. Universidad Autônoma Chapingo - Gobierno Del Estado de Yucatan. 1993. 53p.

CARVALHO, N.M.; NAKAGAWA, J. Sementes: ciência tecnologia e produção. 4.ed. Jaboticabal: FUNEP, 2000, 588p.

CISNEIROS, R.A.; MATOS, V.P.; LEMOS, M.A.; REIS, O.V.; QUEIROZ, R.M. Qualidade fisiológica de sementes de araçazeiro durante o armazenamento. In: Revista Brasileira de Engenharia Agrícola e Ambiental. Campina Grande-PB, DEAg/UFCG v.7, n.3.p.513-18. 2003.

FERREIRA, S. A. N.; GENTIL, D. F. O. Armazenamento de sementes de camu-camu (Myrciaria dubia) com diferentes graus de umidade e temperaturas. Revista Brasileira de Fruticultura. dez. 2003, vol.25, no.3, p.440-442.

GÓMEZ-CAMPO, C. Conservación de semillas a largo plazo: teoría y práctica. In: XI Reunión Latinoamericana de Fisiología Vegetal / XXIV Reunión Argentina de Fisiología Vegetal / I Congreso Uruguayo de Fisiología Vegetal. 22-25 de outubro de 2002. República Oriental Del Uruguay. Ediciones Del Copista. Actas...p.20. 2002.

OLIVEIRA, I.V.M.; ANDRADE, R.A.; MARTINS, A.B.G. Influência do armazenamento na precocidade de germinação de sementes de mangaba (Hancornia speciosa). In: XLIX Reunião Anual da Sociedade Interamericana de Horticultura Tropical. FortalezaCeará-Brasil. Anais... p.102. 2003.

OLIVEIRA, I.V.M.; ANDRADE, R.A.; MARTINS, A.B.G. Influência do armazenamento na germinação de sementes de umbu (Spondias tuberosa). In: XLIX Reunião Anual da Sociedade Interamericana de Horticultura Tropical. Fortaleza-Ceará-Brasil. Anais... p.107. 2003.

POPINIGIS, F. Fisiologia da semente. AGIPLAN, Brasília, 1985. 289p.

VERTUCCI, C. W.; ROOS, E. E. Seed storage, temperature and relative humidity: response. Seeds Science Research, Kew, v. 3, n.3, p. 215216, 1993. 